\title{
Erratum to: Grafting polyacrylates on natural rubber latex by miniemulsion polymerization
}

Lakshimanarayanan Ragupathy • Ulrich Ziener • Robert Graf • Katharina Landfester

Published online: 19 August 2011

(C) Springer-Verlag 2011

Erratum to: Colloid Polym Sci

DOI 10.1007/s00396-010-2360-1

The original version of this article unfortunately contained some mistakes. The corrected author names are shown above.

The online version of the original article can be found at http://dx.doi. org/10.1007/s00396-010-2360-1.

L. Ragupathy $\cdot$ R. Graf $\cdot$ K. Landfester $(\bowtie)$

Max Planck Institute for Polymer Research,

Ackermannweg 10,

55128 Mainz, Germany

e-mail: landfester@mpip-mainz.mpg.de

U. Ziener

Institute of Organic Chemistry III/Macromolecular Chemistry,

University of Ulm,

Albert Einstein Allee 11,

89081 Ulm, Germany 